\title{
CYBERSPACE VERSUS CITIZENSHIP: IT AND EMERGING NON SPACE COMMUNITIES
}

\author{
S.E. Little \\ Department of Business Systems, \\ University of Wollongong
}

This paper was developed from one presented at the Cities Cultures Conference, Brisbane, December 1992

\begin{abstract}
In 1964 Melvin Webber challenged the notions of community and centrality used in urban studies by demonstrating that "community without propinquity" was emerging within certain social networks. He argued that individuals were enmeshed in an overlapping range of groups, and that increasingly these social networks were not limited by physical or geographical location. His definition of community acknowledges a differentiated range of "non-place" cultures. It reflects a change to a process, rather than product oriented view of urban form, triggered in part by the influence of general systems theory. Webber influenced and was influenced by the emergence of an orientation towards non-physical aspects of community, and a participatory approach to design which emerged strongly during the seventies. Reexamination of Webber's work in the light of current information technology offers some insight into the nature of the globalisation of the world economy, and consequent impacts on nationality and sovereignty. The technologies that will be commonplace by the end of the century can both empower and disempower and it will be necessary to reconsider our current notions of both citizenship and of access to and control of such crucial resources. Opportunities offered by IT for marginalised or peripheral groups, whether at the level of nation, region or local community, will challenge existing definitions of centre and periphery. The moral panics surrounding such activities as "hacking" and its supporting "cyberpunk" sub culture demonstrate a growing awareness of the importance of emerging non-space communities.
\end{abstract}

\section{WEBBER'S FORMULATION OF NON-PLACE REALMS}

Webber's 1964 paper addresses "metropolitan planning", in an attempt to move away from the agenda of city planning with its focus on "small scale physical aspects of urbanization" (Webber; 1964, p.80). He suggests his view is

"oriented to metropolitan processes (a verb view) from which it seeks to identify the matching spatial form (a noun view), and hence it seeks to pose a dynamic portrait of metropolitan form in action (a gerund view).

(Webber; 1964, p.80, emphasis in original)

Webber's argues that the physical preoccupation of urban theory creates inadequacies. A processoriented re-evaluation of the components of urbanism that planners and architects claim to support and promote is therefore required. Urban communities are presented as spatially structured processes, with the physical fusing of US Atlantic seaboard settlement providing a striking example of the outcome of such processes.

In order to move from the physical bias of established planning conceptions, Webber proposes the "city as communications system" (Webber; 1964, p.84). Planners "share a conviction that the physical and locational variables are key determinants of social and economic behaviour and of social welfare" (Webber; 1964, p.85). According to Webber, the unique commodity offered by the city is accessibility and he cites Meir's (1959) development of a system of social accounts as the basis of an index of cultural wealth reflecting the volume and variety of information flowing through public communication channels (Webber; 1964, p.87, note 9). Such an approach switches the emphasis of urbanity from physical built form to the quality of interaction in cultural life through the 
exchange of information. Webber argues that this definition implies that suburban and exurban dwellers enjoy a measure of urbanity not previously acknowledged.

In established practice plans are formulated in spatial terms, with a view of social and spatial interaction derived from an examination of population distribution and density. However, Webber argues that such an approach is poorly equipped to account for "dynamic, locational patterns of human communication that occur through space but transcend any given place" (Webber; 1964, p.90). Increasing sophistication in measures and classification of activities still leaves them short of transcending an essentially static picture, even if such "snapshots" may be strung together to reveal changes over time.

Webber argues that planning must deal effectively with three components of metropolitan social structure:

\section{1: spatial flows of money, people and goods \\ 2: location of the physical channels and adapted spaces that physically house activities \\ 3: locations of activity places \\ (Webber; p.96)}

He suggests that first component can be derived from the effectiveness with which communications systems may substitute messages for physical movement of persons or goods (p.97). He cites the significance of railroad location in North American development as an indication of the importance of the second component in determining urban form. The subsequent significance of street car and suburban lines, and freeways suggests that developments in telecommunication capability and capacity had been equally instrumental in freeing access and range of locational choice. Face-to-face communication is still seen as a special need, and traditional central locations are still sought for many forms of business. The permanence of building stock, as well as the character of interaction is significant here, but the creation of this building stock is still regarded as an end in itself by architects and urban planners. The third component is approached through the traditional land-use view of development.

Webber provides a descriptive schema for spatial structure using these three components, and points out that "(p)atterns of functional interdependence will become increasingly complex at the same time that major developments in transportation and communications systems will be opening up unprecedented possibilities for whole new spatial patterns." (p.107).

Earlier notions of "place" in planning are less than helpful: the functional processes which must be acknowledged are not "place-like" or "regional-like" at all. Webber therefore formulates a "nonplace community" in terms of Interest-Communities. Accessibility, rather than the propinquity aspect of "place" is the necessary condition for this form of community (p.109). Extensive webs of specialised professionals can be regarded as communities without propinquity. While specialised professionals are acknowledged to be at one end of the spectrum of residents in a metropolitan area, many other similar association patterns may be detected in non-professional communities. The pure or traditional community is assumed to be relatively heterogeneous, with a unity arising from the pursuit of overlapping interests at a common place. Webber argues that such a "place community" is in fact a special case of a larger genus. With developments in technology and education allowing wider participation in non-place 'groups a hierarchical continuum from highly specialised communities spanning the entire world via less specialised intra-national networks, to metropolitan and neighbourhood networks may be envisaged. Individuals can expect to play roles at a number of these levels at any one time. At each level, the appropriate spatial field is shared by a number of interest communities, and Webber calls such levels of interdependence and interaction "urban realms" (p.114). These are distinguished from the established notion of an urban region by its lack of specific spatial location.

Webber argues that if an analysis of the distribution of each individual's time between realms were possible, it would reveal that rich and diverse human communication was present in conditions of low density and low concentration. He suggests that, in his terms, the urbanity of Los Angeles may not be very different from that of New York. Webber argues that certain approaches to the classification of urban centres were more amenable to the consideration of the range of interactions which he identifies, but that any reconsideration of definitions of centrality in the terms outlined by him would call into question the traditional notions of centre and hinterland, citing locational decisions of emerging high technology companies in California at that time. 
Webber discusses the empirical difficulties of estimating proportions of working hours in an economy by roles and realms, however, any number of the range of qualitative techniques may be appropriate to the task of evaluating the range and intensity of participation of individuals. He ends by suggesting that emerging institutional changes and technological developments coupled with ever increasing mobility and specialisation are likely to involve urban dwellers in increasingly wide area communications, consequently both behavioural models of individual locational decisions, and descriptive models of overall spatial structures would benefit from an orientation to communication patterns.

\section{READING WEBBER IN THE NINETIES}

Clearly much has changed in the thirty years since Webber's paper appeared. Rosenberg (1982) illustrates the problem of being even partially right in technological forecasting by quoting a late nineteenth century prediction that ultimately every American city would be provided with a telephone. Webber (1968) cites significant high speed surface and air transport developments, although the SST and not the Jumbo is mentioned and mass air travel is not discussed. However, improved communications, including public real-time access to computerised databases are identified as potentially critical developments. Toffler's (1970) pro-technology assertions were subsequently given fictional form by science fiction writer John Brunner. However the predicted world of "Shockwave Rider" (1975) in which it was possible to exist in the interstices of a massive computerised domestic credit and surveillance systems had been exceeded by Clifford Stoll's factual account from the end of the eighties (Stoll; 1989). Billed as a new kind of detective story, the latter describes the global pursuit of miscreants across several international computer networks, while Brunner's fictional twenty-first century network was confined to the U.S.A.

Information and communication technologies are by no means the first spatially significant technologies to impact on the nature of national sovereignty. Headrick (1981) demonstrates the key role of technologies ranging from transportation to medical prophylaxis in this extension of the influence and sovereignty of the European powers and the globalisation of that model of the state. Continued development in technology and economic scale has led both to the internationalisation of economic activity and to the emergence of environmental consequences beyond the capacity of individual states to manage. The emergence of transnational corporations (TNCs) and the internationalisation of both financial and labour markets have created a rapidly evolving world system currently characterised by progressive integration at a world scale. Camilleri \& Falk (1992) argue that power and authority have become diffused with national states participating in a variety of multilateral arrangements covering not just trade, production and finance but also increasingly interrelated environmental and security issues.

The key issues which have emerged since Webber wrote can be categorised as those of the development of the big technologies driving the processes of globalisation and those of the small scale implementations of those technologies facilitating local and regional initiatives.

The big technologies include the complex wide area networks which support global business exchanges and global broadcasting: synchronous satellites, fibre optic networks, massively distributed computing facilities, such as INTERNET. Here an institutional perspective is needed to understand the driving concerns which are shaping the emerging "new world order". The small implementations are those points at which entry cost is low enough for individuals and small groups, in some cases because they piggy-back from existing infrastructures. The yuppie symbols of the fax and mobile phone, for example are sufficiently close to existing technical experience for users such as self-employed trades people to successfully appropriate. The size of the Australian economy has been one of several factors influencing the rapid and complete diffusion of earlier forms of information technology. Within this economy the significance for employment of small and very small business is becoming more widely recognised. Some of the most radical changes to work practice may be found in the smallest, one and two person business organisations.

\section{JOINING THE NON-SPACE COMMUNITY}

Castells (1990) has produced one of the most influential analyses of the locational implications of information technology. He argues that a range of contingencies is required to create an appropriate milleu which will allow a region to participate fully in the range of infomrational activities. However, if local and regional initiatives are to be possible, then the notion of an intermediate or 
appropriate entry point to the technology becomes central.. Engagement in a non-place community does not depend on the big technologies, rather on appropriate use of a range of technical opportunities. The question of what can be achieved by a relatively small player in terms of influence over the emerging new "techno-economic paradigm" (Perez; 1984) is crucial to a highly urbanised country the size of Australia. In the social use of this technology we must also ask what leverage we can achieve in the influence of outcomes. The perspective that is appropriate here is that of the seventies "intermediate technology " movement which developed in the decade following Webber's paper, in conjunction with concepts of participative design and community action.

Suchman (1986) has looked at the collective and collaborative use of computer systems by groups of users, breaking with a human-computer interaction research tradition which has emphasised useability of systems in terms of the performance of individuals. The concept of ComputerSupported Collaborative Work (CSCW) reflects the move from an individual to a collective view of users in a socially constructed workspace which includes computer-based information systems. Such technically created non-spaces for both work and social activity can be achieved with relatively unsophisticated equipment. The evaluation of the use and impact of an experimental computer bulletin board on people with disabilities (cerebral palsy) illustrates one paradigm for a diverse range of minority users and their relationship with information technology and the opportunities it affords.

A full account of the study in which clients and therapists in an Australian Spastics Centre were linked with computing students for a period of three months is available in Earls (1990). One striking feature of the findings was the contrast between short term results which reveal no change in attitude over a three month period and the significant changes revealed by a repeated application of the Measurement of Attitude Towards Disabled Persons Test (Yuker, Block \& Campbell; 1960) after two years.

Initial results revealed a slight lowering of self image by the board users at the end of the experimental period. After two years, however, case-studies revealed individuals who had become politically active, gained employment (over $50 \%$ of the experimental group), taken up further study and begun to live independently. These clear benefits also evoked positive changes in their peer group, structural changes in the organisation and a response from the Federal government.

Earls' findings emphasises the importance of longitudinal studies. Vitalari (1985) argues the need for such an approach in the broader investigation of computing environments and Sproull and Kiesler (1991) contrast the short and long run implications of computer-based communication within groups.

For the mainstream too, benefits are both long term and qualitative in nature. Arguments are currently being advanced that quantitative evaluation often fails to reveal any measurable increases in organisational performance following investment in information technology. Despite the continually falling costs and growing flexibility of computer technology there is considerable debate over the realisation of its potential benefits by organisations (eg. Hartamis \& Lin; 1992, Kling; 1993). Much of the argument is around the way in which the core concerns of computer science should be broadened to encompass the useability and usefulness of its products. The skills required to assess and monitor the practices and requirements of end-users are now recognised as very different from the technical skills required for the development of a technical infrastructure.

Strategies favourable to minority users within a local community may be appropriate to national players in the global community. For example, the impact of the relatively simple bulletin board technology highlights the need for any minority group to utilise features of mainstream technical developments as far as possible in order to minimise the use of relatively expensive small volume specialised hardware and software. However, such windows of opportunity may be inadvertently closed by the momentum of mainstream technical development. The features which were of advantage to this particular group, such as the "narrowness" of the communication bandwidth which produced a leveling and bland alphanumeric interface, or the asynchronous nature of communication are currently being eliminated in a technology driven push for greater sophistication. Considerable sophistication in the evaluation and use of elements of mainstream technology is needed by any relatively small group wishing to access the potential benefits of a mass solution. Similarly policies of smaller national players must be based on realistic assessments of opportunities and relative advantages. 


\section{NON SPACE, CYBERSPACE AND CYBERPUNK/NEW SPACES, NEW INSTITUTIONS, NEW CULTURES}

Webber's contribution to the centre versus periphery issues raised by recent developments in information technology is to question the value of physical centrality. There is, however, a marked contrast between the telecommuting scenarios of technologically optimistic futurists such as Toffler (1970) and Bell (1979) and the reality of technical achievements.

The potential of computer-based information systems to facilitate or even substitute for organisational structure and standards has been evaluated from a variety of social and organisation theory perspectives. Little (1988) shows how very different strategies may be pursued with the same equipment, but that technical developments may lag behind organisational ambitions. Sproull and Kiesler (1991) emphasise the difference between immediate technical gains from such technologies and the longer term process of social gains for organisations. Specific technologies like computeraided design may substitute for organisationally enforced standards, while software standards and electronic date interchange are increasingly presenting organisations with externally derived standards and procedures.

The ethnocentric focus of Webber's original paper is reflected by the equation of modemism with Western (US) urban forms and structures which are seen as the end product of a process of social evolution. Castells (1990) readily acknowledges a US focus in his data. Clegg (1990) indicates how North American organisational forms are still regarded as a norm, and argues that cross cultural examination of alternative organisational form, building on Lammers and Hickson (1979) is necessary to evaluate the full range of available possibilities.

Belussi (1989) describes the utilisation of a number of technical strands by the Benetton company which result in a computer-based network which is both transnational and trans-organisational in extent. In this example, ownership and control of the core of the information network substitutes for ownership of production and distribution and for a formal hierarchy. The core of this enterprise is an information system linking a network of worldwide franchised retail outlets and a network of subcontractors who provide the wholesale products.

Developments in transnational work organisation and telecommunications have allowed real-time off-shore location of white collar work from the U.S. mainland to the Caribbean and less dramatically have facilitated a division between "front office" tasks which remain in the prestigious CBD and "back office" tasks, often involving part-time and female workforces relegated to the periphery of suburbia (Nelson; 1988). While information technology appears to offer a means of redressing relative locational disadvantage, experience so far suggests that the impact on locational mobility has been overestimated for the majority of the working population. Webber himself discusses the relative disadvantage of the "by-passed preindustrial locals" (Webber; 1968, p.1101), and the elite component of the workforce required by transnational corporations (TNCs) may be the only actors fully to meet Webber's definition of non-space interest communities.

The critics of the urban planning of the seventies attacked redevelopments that privatised previously public spaces, yet the virtual space of computer networks is primarily private, with the deregulation and privatisation of common carriers widening this trend. The process of globalisation and deregulation has accelerated the privatisation of this infrastructure. Emerging technologies and concepts such as Virtual Reality and computer supported collaborative work (CSCW) offer the prospect of the annihilation of physical separation, but at a price, and at the cost of excluding a significant minority of a region's citizens. Any attempt to redress such shifts on behalf of local or regional interests requires an alternative paradigm to that of the technological optimists.

Recognition of the existence of "cyberspace": a non-place realm of computer-supported relationships has taken Webber's original conception considerably further. Benedikt (1991) traces the term to William Gibson's dystopian novels (Gibson; 1984). The cyberpunk culture which has grown around the themes first articulated by Gibson has both utopian and dystopian strands.

The physical non-space aspects of ARPANET, the original national research network in the United States are a striking indication of how far such tendencies may take organisations. The operating software could relocate itself across its own network to the least busy host machines. Such non-space aspects of "netland" have been exploited by "cyberpunk" enthusiasts but have also attracted more respectable attention from a number of researchers. For example, Canter and Perin are applying respectively their cognitive mapping and environmental psychology methods developed $n$ the seventies to the mental images and organisational relationships developed by users of complex interactive computer systems (see Canter; 1977, Perin; 1970, 1991). 
In a post-cold war environment it is clear that a number of institutions are reassessing their roles. Some cold warriors are viewing this non-space arena as their new fiefdom. The National Security Agency has become deeply involved in the development of data verification and encryption, to the extent of proposing software and standards for commercial transactions. control of the encryption standards would enable them to monitor traffic. The proposals have been vigorously opposed by groups such as Computer Professionals for Social Responsibility (CPSR). NASA has similarly become involved in a reconfiguration of SDI or "Star Wars" projects which are directed not at the defence of the United States, but at denial of near-earth space to competing nations. They are effectively policing the infosphere for one nation's benefit.

If the CPSR can be regarded as a nineties equivalent of the ACLU or the NAACP, then the demonised hackers of the networked world may yet emerge as the equivalent of the Black Panthers and urban guerrillas of the sixties. The phenomenon of "hacking" is indicative in part of resistance to emerging patterns of ownership and control. In their naivety these technophiles have become Luddites subverting rather than attacking the technological base of a "new world order" with slogans such as "information wants to be free". The demonisation focuses on genuinely criminal and destructive activities by a minority of the "cyberpunk" sub-culture within computing circles. However, such activities themselves grew out of the fringes of the anti-war movement in the U.S.A. in the late sixties and early seventies, with the traditional telephone system being the first target for the "liberation" of resources (see Bowcott \& Hamilton; 1990).

This sub-culture has become the first example of an increasingly global non-space community inhabiting the "virtual space" of communication networks. It became global as the technological base has diffused from the leading nations. A great deal of traffic across the networks in the summer of 1991 originated in Russia and described the events of the abortive coup to the outside world. In China, following the suppression of the democracy movement in 1989 there was a massive increase in the incidence of computer viruses. In Britain at the height of the anti-Poll Tax campaign an elaborate hoax was staged to persuade local authorities that a computer virus had been introduced in order to corrupt the databases essential to the collection of this unpopular charge.

The cyberpunk literature emphasises the intellectual and cultural possibilities of the emerging global "non-space realm". It provides an alternative vision to the privatising economic rationalism that has arisen with the mainstream. Paradoxically it also draws attention to the critical qualitative features of the technology that will be central to its effective commercial and economic use.

\section{CONCLUSION}

The "global village" concept, itself a cousin of Webber's non-place realm, and the culturally acceptable face of globalisation, represents a top down diffusion of cultural hegemony. Only now can the diffusion of information technology at various levels of sophistication support a possible twoway traffic. At the same time the concept of nation state has become problematic. The nineties is developing as the decade of the revival of subnational and regional sovereignties. These are readily supported by developments in global communication technology. The most striking example was the briefly canvassed suggestion during the Iraqi occupation of Kuwait that the dispossessed national government might continue to function on the world financial markets without access to its country, but with electronic access to its funds.

Jane Jacobs was one of the first to report the negative effects of applications of modern urban planning theory in terms that affected the popular consciousness of the sixties (Jacobs; 1962). She illustrated how the strict hierarchical decomposition of mainstream land-use planning failed to acknowledge either long established economic mechanisms, or more recent changes in the nature of industry and employment which made rigid separation of housing, industry and commerce less important than accessibility and diversity.

Twenty years later Jacobs (1982) discusses the development of Quebec separatism in a global context. Subnationalism can be seen as an inevitable outcome of changes wrought since 1964 . Webber (1968) argues that the replacement of the city state by the nation state weakened the power of the traditional urban community. Despite European Community funded research includes a substantial programme addressing definitions of citizenship, the difficulties over ratification of the Maastricht Treaty indicate the lack of any clear consensus between and within member states.

Supranational government may revive city and regional status, as it erodes the status of national governments. Experience with the development of transport informatics in support of road pricing policies suggests that direct negotiations between European Community institutions, metropolitan 
governments and trans-national corporations may diminish the influence of national governments over crucial standards for information and communications technologies. Ohmae (1990) argues that regional and city level interests have replaced direct international competition. However the question remains how powerful these new "city states" might be in the face of direct competition with their neighbours for the attention and resources of TNCs. He suggests that TNCs strive for a position of "currency neutrality" so that relative shifts of exchange rates have a negligible impact on their activities. Similarly location policy is also informed by the potential formation of trading blocks, and facilities and resources are planned so that operations are self-sufficient within each potential block.

Webber cites the growing importance of non-governmental and specialised governmental groups and bodies in urban life. Industry and de-facto standards as well as formally agreed international standards are key elements of the emerging supranational infrastructure, just as railways, roads, and national telecommunication carriers were cited by Webber as historically significant influences on locational decisions by individuals and organisations. In this context, the widespread deregulation of national telecom carriers may mark the final decline of purely national sovereignties. As these are prepared for privatisation their social role of equalisation of spatial disadvantage is usurped by the need to compete for the core, profitable markets. Already one national Australian bulletin board has had to relocate to a capital city because of a concentration on lucrative urban markets and a reduction of its redistributive role by the national carrier. Local governments must now compete for the early availability of new communication resources, just as they one competed for access to railway routes. The situation is even more problematic in countries such as Russia where unfettered privitisation has been unleashed in a situation of much greater existing inequity between centre and periphery (Giglavyi; 1993). Press (1992) cites Landweber's calculation that 129 of 236 political entities still lack any direct connection to this global club. They effectively lack a basic ingredient of world citizenship.

Gender was little theorised in relation to the application of technology in the sixties, and Aungles (1992) demonstrates how it can still be largely ignored in technological debates through her examination of the impact upon families of electronically monitored domestic detention. When coupled with Sewell and Wilkinson's (1992) analysis of electronic surveillance in the workplace, Aungles' work shows us a complete penetration of both the domestic and employment sphere by the technologies of commerce.

Clearly at the levels of both national and personal life there is an imbalance in power reflected in access to the key technologies of ther emerging non-space realms. The technology itself is not the threat to established conceptions of citizenship, however. Margaret Thatcher attributed the 1992 U.K. general election result to the removal of up to one million voters from the register through their avoidance of the Poll Tax (Hodgson; 1993). This is an example of the application of user-pays principles to what previously were regarded a basic civil rights.

In this context there may be a positive role for the cyberpunk sub-culture, with its assumption of open access to the non-space of the emerging networks in the facilitation of the collective community action of the seventies through the technologies of the nineties. Webber's paradigm of non-place realms can be linked with that of appropriate technology and windows of opportunity in the formation of that technology. This can provide guidance for the development of appropriate local responses to the globalising pressures resulting from the continuing development and coalescence of advanced information technologies.

\section{REFERENCES}

Aungles A. (1992) "Electronic Surveillance and Organisational Boundaries: the Home as the Prison" in Aungles S. (ed) Information Technology in Australia Kensington: University of New South Wales Press

Bell D. (1979) "The social framework of the information society" in Dertouzos M.L. \& Moses J. (eds) The Computer-Age: a twenty year view Cambridge: MIT Press

Belussi F. (1989) "Benetton: a case study of corporate strategy for innovation in traditional sectors" in Dodgson M. (ed) Technology Strategies and the Firm: Management and Public Policy Longman, London.

Benedikt M. (ed) (1991) Cyberspace, first steps Cambridge MA: MIT Press

Bowcott O. \& Hamilton S. (1990) Beating the system: hackers phreakers and electronic spies London: Bloomsbury.

Brunner J. (1975) The Shockwave Rider London: Dent. 
Camilleri J.A. \& Falk J. (1992) The End of Sovereignty ? The Politics of a Shrinking and

Fragmented World Edward Elgar, Aldershot.

Canter D. (1977) The Psychology of Space London: Architectural Press.

Castells M. (1990) The Informational City

Clegg S. (1990) Modern Organisations: organisation studies in the post-modern world London: Sage.

Earls J.A.M. (1990) "Social integration of people with disabilities: the development of an information technology model based on personal growth and achievement" Unpublished PhD thesis, University of Wollongong.

Gibson W. (1984) Neuromancer Grafton Press, Dublin

Giglavyi A. (1993) "IT Landscape in Russia" International Conference on People and Information Technology ITAP'93, Moscow, May 1993.

Hartamis J. \& Lin H. (eds) (1992) Computing the Future: A Broader Agenda for Computer Science and Engineering Washing D.C.: National Academy Press.

Headrick D.R. (1981) The Tools of Empire: Technology and European Imperialism in the Nineteenth Century Oxford University Press, Oxford.

Hodgson G. (1993) "Down a slippery poll" New Statesman \& Society 21 May 1993, pp.18-19.

Jacobs J. (1982) The Question of Separatism London: Junction Books,

Kling R. (1993) "Computing our future for a Social World" Communications of the ACM, February 1993.

Lammers C.J. \& Hickson D.J. (1979) "A cross-national and cross-institutional typology of organisations" in: Lammers C.J. \& Hickson D.J. (eds) Organisations alike and unalike: international and interinstitutional studies in the sociology of organisations London: Routledge \& Kegan Paul.

Little S.E. (1988) Organisational implications of computing for professional work, Aldershot: Gower/Avebury.

Meir R.L. (1959) "Measuring social and cultural change in urban regions" Journal of the American Institute of Planners, Vol.25, August 1959, pp.180-190.

Nelson K. (1988) "Labor demand, labor supply and the suburbanization of low-wage office work" in:

Scott A.J. \& Storper M. Production Work and Territory: The geographical anatomy of industrial capitalism Boston: Unwin-Hyman.

Ohmae K. (1990) The Borderless World: Power and strategy in the interlinked economy Collins, London.

Perez C. (1985) "Microelectronics, Long Waves and World Structural change: New Perspectives for Developing Countries" World Development 13(3) 441-63

Press L. (1992) "The Net: progress and opportunities" Communications of the ACM, Vol.35 no.12 December 1992, pp.21-25

Rosenberg N. (1982) Inside the black box: technology and economics Cambridge: Cambridge University Press.

Sewell G. \& Wilkinson B. (1992) "'Someone to Watch over Me': surveillance, discipline and the Just-in-Time labour process" Sociology 26. 2, May 1992, pp.271-290.

Sproull L. \& Kiesler S. (1991) Connections: new ways of working in the networked organization Cambridge: MIT Press.

Sterling B. (1992) The Hacker Crackdown New York: Bantam.

Stoll C. (1989) The Cuckoo's Egg London: The Bodley Head.

Suchman L. (1986) Plans and Situated Action Cambridge: Cambridge University Press.

Toffler A. (1970) Future Shock New York: Bantam.

Vitalari N.P. (1985) The need for longitudinal designis on the study of computing environments in Mumford E. Hirschheim R. Fitzgerald G. \& Wood-Harper A.T. Research Methods in Information Systems Amsterdam: North Holland.

Webber M. (1964) "The urban place and the non-place urban realm" in: Webber M.M. Dyckman J.W. Foley D.L. Gutenberg A.Z. Wheaton W.L.C. \& Wurster C.B. Explorations in Urban Structure Philadelphia: University of Pennsylvania.

Webber M.M. (1968) "The post-city age" Daedalus vol.97 no.4, Fall 1968, pp.1091-1110.

Yuker H.E. Block J.R. \& Campbell W.J. (1960) A scale to measure attitudes towards disabled persons Human Resources Study No 5 Albertson N.Y.: Human Resources Centre 